\title{
BRIEF: \\ COMMUNITY RESILIENCE: KEY CONCEPTS AND THEIR APPLICATIONS TO EPIDEMIC SHOCKS
}

The COVID-19 pandemic has exposed long-standing social inequalities and vulnerabilities, with the most disadvantaged and marginalised groups bearing the greatest health, social, and economic burdens.' Beyond documenting these vulnerabilities, there is a need to mitigate them and support the resilience of marginalised communities. 'Community resilience' can bolster community capacity to cope with the pressures of various shocks; this brief explores how its concepts can be applied to epidemics. It reviews the grey and academic literature on different approaches to community resilience. It covers 1) terminology, 2) lessons from practice, 3) the context of community resilience, 4) a systems approach, and 5) key human and social capacities. Social justice, inequality, equity, and fairness are highlighted as themes in need of further development for resilience as it relates to epidemic preparedness and response. This brief was developed for SSHAP by IDS (led by Megan Schmidt-Sane with Tabitha Hrynick) with Anthrologica (Eva Niederberger). The brief is the responsibility of SSHAP.

\section{SUMMARY POINTS}

- Building a resilient community generally means adapting and deploying community capacities (or strengths) and resources to proactively mitigate harm during a crisis and to recover from adversity. ${ }^{2}$ Others see it as a continual process of change and adaptation as the environment and stressors change.

- A community is defined here as a group of individuals sharing common characteristics, which may or may not be based on shared geographic space. Communities have complex social dynamics. Resilience programming should address inequalities, vulnerable groups without power, and social tensions within a community.

- Resilience programmes must be adapted to local context. Community resilience is affected by its wider context: geographic, political, economic, and historic.

- Community resilience programs are not a single solution for community vulnerability, particularly during extended crises when community capacities can be overwhelmed. 
Governments should not be absolved of their role as providers of vital services and support. In an ideal situation, both communities and the state should work together to build resilience.

- Equity and fairness in access to resources is necessary to ensure one group is not privileged over others. 'Transformative community resilience' means working to rebuild communities in more equitable and socially just ways.

- Resilience is inherently multisector and multiscale, so building resilience demands a 'systems approach,' as this enables complexity and interconnectedness of vulnerability, livelihoods, and uncertainty to be managed.

- Community resilience can be built to respond to current and/or future threats including health 'shocks' such as infectious disease outbreaks or epidemics.

\section{How can resilient communities be built?}

1. With time: Resilience approaches require long-term engagement (7-10 years). ${ }^{3}$

2. Informed by research: E.g. A baseline resilience assessment can be used to identify existing assets, resources, capacities, and understand vulnerabilities and threats as well as power dynamics and inequalities. This should also capture the complexities of the context. 3,4 For example, Mercy Corps' Strategic Resilience Assessment (STRESS) which analyses context and is used to design a resilience theory of change. ${ }^{5}$

3. By encouraging communities to 'own' the process, and ensuring there is a multisectoral effort: ${ }^{4}$ This means engaging individuals, community, regional, and, where appropriate, national stakeholders. ${ }^{6}$

4. By working with community members to create a theory of change. For example Oxfam uses a Resilience Fundamentals Checklist to do this.?

5. By monitoring and evaluating progress. This may be challenging, however, there are models for doing this. E.g. CARE International has used its Resilience Framework to guide evaluation, ${ }^{8}$ and the Analysis of Resilience of Communities to Disasters (ARC-D) toolkit which supports resilience building interventions. ${ }^{9}$

\section{WHAT IS COMMUNITY RESILIENCE?}

With an unstable and changing climate, emerging disease threats, and increased violent conflict, there is a need to review approaches to mitigating vulnerability and coping with crises. Vulnerability has been defined in different ways, but it generally means the socioeconomic factors (poverty, lack of education, etc.) that make a community or social group less able to cope with or manage stress, crisis, or shock. ${ }^{3}$ Community vulnerabilities and resilience are interconnected. ${ }^{4}$ Community resilience has long been used in disaster management and humanitarian response. A resilience framing resists the idea that communities are passive recipients of assistance or aid, ${ }^{5}$ and instead emphasises their capacities and resources to prepare for and effectively respond to crises. It also proactively prevents and reduces drivers of shocks and systemic issues that drive vulnerability. 
Community resilience has been conceptualised differently as a process, an outcome, or a range of attributes. ${ }^{2}$ It might be a continual process of change and adaptation as the environment and stressors change. A resilient community would be able to deploy and adapt community capacities (or strengths) and resources to mitigate harm during a crisis and to recover from adversity. ${ }^{2}$ Resilience attributes include local strengths and resources, or 'a community's capacities, skills, and knowledge' that allow the community to participate fully in recovery from a shock. ${ }^{6}$ Common terms in this field are presented below in Table 1.

\section{Table 1. Terms in community resilience}

\section{Community}

A community is a group of individuals who share common characteristics (e.g., physical location, common identity, religious or ideological values). This may be based on geography, meaning people living in the same area (a neighbourhood or village, for example). While community is a central unit of analysis in 'community resilience,' it is not always clearly defined and has been heavily critiqued.7 A clear concern is a lack of clarity about what constitutes a community. ${ }^{7}$ A 'community' might reflect artificial boundaries drawn for colonial or political purposes, rather than an actual group with shared history, beliefs, or practices. A simplified notion of 'community' can overlook local realities and undermine efforts to meaningfully reach or involve all affected people in resilience mechanisms. Communities are dynamic and complex, characterised by social differences, divisions and multiple identities, and where local power dynamics are embedded in social hierarchies. Any notion of 'community' in resilience should be understood as complex and contentious.

\section{Adaptability and adaptive capacity}

Adaptability, or adaptive capacity, was originally defined to mean an ability to become adapted (e.g., to live longer and produce offspring) to a certain range of environmental situations. ${ }^{8,9}$ Adaptability, when applied to community resilience, signals a capacity to cope with changes, shocks or crisis; a capacity to improve a community's condition in relation to the environment. This may be through community-level responses to stress that either maintain a community's functioning (homeostasis) or result in short-term changes. ${ }^{8}$

\section{Coping}

It is important to distinguish between an exposure to crisis (e.g., vulnerability) and coping. Coping is defined here not an on individual level, but rather as a community's strategy to take action, ideally collectively, in the face of crisis. ${ }^{6,10}$ This also means mitigating negative coping strategies and promoting positive ones. Negative coping strategies include short-term trade-offs to enable survival, but may result in compromises to well-being and future resilience." In contrast, positive coping strategies accommodate short-term needs without compromising future well-being, or even laying the ground-work for future resilience. 


\section{COMMUNITY RESILIENCE IN PRACTICE: LESSONS LEARNT FROM DISASTER MANAGEMENT AND HUMANITARIAN PRACTICE}

Disaster management. Resilience programmes are most often used in disaster risk reduction, and there has been increasing focus and activity in this area in the past decade.6,12-17 IFRC's work on resilience in the context of disasters envisions a resilient community as one that is knowledgeable, healthy, and can meet its basic needs; is socially cohesive; has economic opportunities; has sufficient infrastructure and services; can manage its natural assets; and is connected to outside stakeholders and resources. ${ }^{18}$ From this and other work on community resilience to natural hazards, a view of resilience has emerged which focuses on three areas: reducing impacts or consequences of a shock, reducing recovery time, and mitigating future vulnerabilities. 19,20

Box 1. Concepts in the field: Community partnerships for resilience and disaster risk reduction In the wake of Hurricane Maria in Puerto Rico, Mercy Corps and its partners came together with local community organisations to build Resilience Hubs across the island. Communication was identified as a key tool needed during a disaster to share information, deploy resources, and access emergency services. Mercy Corps and its local partners trained community members on how to use these communication systems and the Resilience Hubs were supported to develop long-term sustainability plans. When community partners are meaningfully engaged, local needs can be more easily identified and addressed.

Humanitarian practice. Types of community resilience and community needs vary according to the type of shock. ${ }^{21}$ For example, during conflict, researchers in Syria identified several factors contributing to communities' capacity to absorb shocks psychological strength and social networks were as critical as savings, cash and assets. Also, a higher degree of preparation for conflict improved people's decision-making capacity and 'sticking together in these decisions' was found to be an important enabler to better cope with the shock. Social capital is a driver of resilience contributing to communities' transformative capacity.22,23 Social cooperation and solidarity may however degrade according to the type and length of crisis, and may change over time. ${ }^{24}$ IRC's work on resilience ${ }^{25}$ recognises the social network as very important, especially for more vulnerable communities, e.g. women, youth, or the differently abled. Based on their research, social networks were positively correlated with women's success as entrepreneurs and this correlation is even stronger, at times, than business training and women's success as entrepreneurs.

\section{Community resilience in practice: Epidemic preparedness and response}

The threat of emerging infectious diseases, including zoonotic diseases, and the increasing prevalence of diseases previously controlled by antimicrobials and vaccination, 
is a cause for concern. Communities play an essential role in prevention, early detection and early response of such threats. ${ }^{26,27}$ In a 'whole-of-society' approach, they help contain and control infectious disease threats, limiting geographic spread, saving lives, and mitigating negative impacts. Global health security requires inclusive and collaborative efforts that capture and build on the interdependencies between communities and their natural environments, civil society, the private sector and governments to ensure success.

Lessons learnt. Examples of building community resilience with regard to disease outbreaks is less widely documented than other types of shock. In Liberia, during the West African Ebola epidemic (2014-2016), communities with strong social bonds were particularly resilient. They were able to draw on their social cohesion to mobilise collectively, including instituting their own surveillance programmes, pulling together resources to care for the sick, and transport them to health facilities before external help arrived. ${ }^{21}$ While the concept of 'community resilience' was not explicitly used, community level actions, dynamics and behaviour change were seen as crucial in helping to turn the crisis around. ${ }^{28}$ However, often emergency aid has been provided for specific activities as determined by external actors, without input or consultation from community members. ${ }^{21}$ An important lesson from past experience is that communities themselves should be central to decisions about how resources are used and response is carried out. Early in the West Africa Ebola epidemic, the IRC called for placing community leadership at the centre of the Ebola response..$^{29}$ Later, the organisation noted that their Ebola response programmes were only successful because they engaged communities. The IRC's medical anthropologist and psychosocial team explored and reported on concerns, fears, beliefs, and engaged communities in response activities.

Communities at the centre of resilience. While attention to community resilience amidst a health emergency is one thing, developing or rebuilding it during more stable periods -to better prepare for future potential crises as well as to heal from past ones - is also important. Community members are the first to know when an unusual health event has occurred around them. So, enabling, empowering, and equipping them to recognise and respond to public health threats makes sense and forms an essential pillar of an integrated approach to epidemic preparedness and response. ${ }^{30}$ For example, the IFRC's Community Epidemic and Pandemic Preparedness Program (CP3) aims to strengthen the ability of communities, Red Cross Red Crescent National Societies, and other partners in eight target countries to prevent, detect, and respond to disease threats and prepare for future risks. Resilience is a core focus of this programme. ${ }^{31}$ 


\section{THE CONTEXT OF COMMUNITY RESILIENCE}

While community resilience tends to focus on a local level, we must understand the wider context in which a community is embedded (politics, economy, histories) and how these affect a community's ability to withstand crises. ${ }^{21,32,33}$ Resilience literature largely focuses on humanitarian contexts or areas prone to natural hazards; there is a need to conduct more research on how community resilience can be built in other contexts, particularly in urban areas. ${ }^{6}$

There may be a tendency to idealise community resilience as a solution in the absence of state support and state services. Resilience as a concept has been criticised as overtly neoliberal, putting the onus on communities to recover while absolving the state of responsibility. ${ }^{34}$ This brief contends that communities should be resilient, but governments cannot be released from their role as providers of vital social services and support. Both are vital in order for communities to be able to absorb, adapt, and recover from shocks. The focus is often about 'returning to normal' as soon as possible, bouncing back and relying on established models of resilience based on the management of economic risk. However, there is an opportunity to shape the discourse by supporting, simulating and modelling community-led responses that build trust, imagine resilience and engagement with large sections of communities such as civil society, business, and social networks differently. A 'return to normal' may not be beneficial for all, especially those who experience marginalisation within their community. ${ }^{35}$ Rather, community resilience should aim to be transformative. ${ }^{36}$ These key issues are embedded in the evidence presented below.

Local politics and power. While health and humanitarian response practitioners can engage in strategies to support communities to be more resilient, this may be difficult to sustain in the absence of local government support. As a positive example, Mercy Corps noted that the local Mahjia system and community leaders in Cox's Bazar played a significant role in enabling access to information, support, and services, and thus providing an enabling environment for continued resilience." As such, social and power relations and local politics are vital to consider in a community resilience approach. However, both visible and invisible power relations can affect how and under what conditions vulnerable groups are able to participate in community systems. ${ }^{37}$ Through

a The Mahji are army-appointed block leaders in refugee settlements in Bangladesh who are tasked with settling minor disputes whereas severe cases are handled by government officials or stakeholders in charge. 
one programme in Laos, village livelihood development grants were given to individual households to shift agricultural practices toward sustainability. However, members of village authorities were more connected to these interventions, which led to their greater power in deciding who received grants. While it a ppeared that those who received grants (e.g., village authorities, men, ethnic majority members) became more resilient, this outcome masked the initial privileged access they enjoyed. ${ }^{37}$ Meanwhile, other villagers like women, ethnic minorities, and poorer village residents did not receive grants. Understanding this context of community resilience is vital and leads to a more holistic understanding of the systems that drive vulnerability or enable resilience. It is good programming practice to analyse power dynamics and structures prior to launching interventions, so activities do not further entrench power. However, we also recognise the difficulty of changing social norms, especially in emergencies.

Local inequalities. Inequalities within a community affect who participates in and benefits from community resilience." Gender inequality poses a challenge to community resilience and influences how individuals experience shock and the mechanisms used to cope with shock. Mercy Corps has emphasised the need to address gender inequality, by increasing women's and girls' access to different forms of financial capital to improve their resilience. ${ }^{38}$ CARE International conceptualises improvements in gender equality as one way to improve resilience. As such, in Papua New Guinea, CARE worked with traditional male leaders to restructure village assemblies and decision-making processes to increase women's participation. This led to women's increased role as decision makers in the community and more control over resource allocation. ${ }^{39}$ The IRC created pre- and postdistribution survey tools and activities that help to mitigate the risk of entrenching these inequalities.

Other work has highlighted the role that disasters or other shocks may play in worsening inequalities and vulnerabilities. ${ }^{35,40,47}$ Marginalised populations within a community face greater exposure to shocks, and inequalities and power imbalances can leave these groups without space to participate in planning a response. ${ }^{42}$ Research on homeless populations in Denver, Colorado in the wake of a flood highlighted how social inequalities limit the livelihood options (and capacities) of vulnerable groups, leading them to live in more hazardous environments and 'constraining their abilities to cope' with shocks. ${ }^{35}$ Resilience programming can identify and support locally vulnerable groups in need of additional support.

Transformative and social justice-oriented resilience. There is a danger that resilience programming may overlook or even entrench existing unequal power relations within communities. To avoid this, resilience should address equity, fairness, and access to 
resources so that one group is not privileged over another ${ }^{43}$ and this should be part of a baseline resilience assessment. Some have argued that a community resilience paradigm primarily benefits those who are already well-off, sometimes at the expense of the already vulnerable and assessing this at the outset is critical. ${ }^{44-46}$ Understanding the intersections of vulnerability is critical to better understand and address experiences of disaster, conflict, or health shocks. ${ }^{47}$ Rather than returning to normal, or the "previous state of lifestyle,'48 social justice can and should be addressed in resilience programmes so that the needs of the vulnerable are better met both in the short and long term.

\section{RESILIENCE USING A SYSTEMS APPROACH}

A systems approach (Box 2) provides a framework for developing resilience simultaneously across sectors (government, non-government, humanitarian) and at multiple scales (individual, household, community). ${ }^{49}$ It explicitly acknowledges and addresses the interconnections between social, environmental, and other relevant systems. ${ }^{50}$ Individual and household resilience capacities are nested within community resilience capacities, which are, in turn, nested within systems. In other words, working on the resilience of critical systems recognises the importance of those systems in supporting community-level resilience.

The COVID-19 pandemic illustrates how crises are multi-dimensional and how it is essential to strengthen community resilience holistically. COVID-19 has created health, economic, and social crises as vulnerable groups have been disproportionately affected., ${ }^{1,40,51}$ To build community resilience holistically, it is vital to understand sociocultural, political-economic, and environmental drivers of community vulnerability to epidemic shocks through a baseline assessment. A whole systems approach to community resilience requires good baseline information and a shared understanding of local assets and vulnerabilities. ${ }^{52}$ It also recognises how resilience capacities are interconnected and mutually reinforcing. Examples of resilience systems, all equally important to addressing community resilience, are described below:

- Health systems resilience emerged from literature on the 2014-2016 West African Ebola epidemic. ${ }^{53-56}$ In addition to improved preparedness and response in the face of shocks, increased resilience across health systems, including in the community, provides a 'resilience dividend' in the form of improved routine healthcare, strengthened social bonds and productivity during non-outbreak periods. ${ }^{55}$ Health systems are resilient at the community level when community health workers are well supported, with timely salary payments, sufficient equipment and supplies, and their other needs are met. 
- Market systems resilience is a relatively unexplored area of resilience. Markets are a central part of the resilience ecosystem and will play a key role in supporting both household livelihood strategies and community-level resilience. ${ }^{57}$ Market system resilience is the ability of market systems to 'allocate resources, draw on system-level resources (e.g., social safety nets, government assistance), and innovate' in order to mitigate shocks. ${ }^{58}$

- Food systems resilience refers to a food system that is able to withstand and recover from disruptions in a way that ensures a sufficient supply of acceptable food for all.59 During times of crisis, food systems are often rapidly disrupted through food shortages, food losses, or price volatility. ${ }^{60}$

Box 2. Concepts in the field: A systems approach

Mercy Corps increasingly considers resilience within the broader system. Their recent work in urban centres has shown how important it is to look at relevant sectors within a context and define how they can be used to mutually reinforce a resilient community. In Lagos, Nigeria, urban youth are a vulnerable population more affected by flood risk, over-policing and police brutality, drug use, cultism, and low quality, high density housing. Mercy Corps' resilience assessment found that taking a resilience approach would include building skills and capacities to advocate for protection, formalisation of labour and improved labour standards, improved community disaster risk reduction capacities, and improved livelihoods.

\section{RESILIENCE CONSIDERS HUMAN AND SOCIAL ASPECTS}

The theory of community resilience incorporates human and social capacities, including local knowledge, community networks and relationships, communication, governance and leadership, and resources. These capacities can be built prior to a crisis and drawn upon during a crisis to mitigate harmful effects and promote resilience during epidemics.

Local knowledge is a capacity used by communities to sustain their lives and livelihoods. ${ }^{67}$ It includes 'experience- and community-based knowledge' of social groups (such as indigenous, marginalised, and other vulnerable groups). ${ }^{62}$ Local knowledge should be used to inform epidemic response.2 Social science research has documented local knowledge on infectious disease threats and how communities have managed or adapted to manage threats. ${ }^{62-65}$ This might include knowledge of how to respond at the local level, when to refer to a health facility, and how to recognise what is an emerging health threat. During the 2000-2001 Ebola outbreak in northern Uganda, the world's largest at the time, the Acholi activated a customary system to identify, isolate and care for the sick, and bury the dead within their own social and spiritual framework, and using locally available materials. ${ }^{66}$ In West Africa, local leaders and communities undertook and planned activities for community-led prevention, response and recovery in the absence 
of external support, 67 including through a 'people's science' of learning and experimentation. ${ }^{68}$ This work has largely not been linked to community resilience programming. It is important to understand existing local knowledge and co-design new adaptive capacities in community resilience programming. ${ }^{69}$ One example is IFRC's eCBHFA which helps communities to identify their health-related risks and capacities, and build from those through local volunteers and community health workers, complementing formal health systems. ${ }^{70}$ IFRC also uses the Epidemic Control for Volunteers manual and toolkit to train volunteers on epidemic risk management in their communities. ${ }^{71}$ Lessons from past work on resilience from other crises (Box 3) can be adapted for epidemic response and recovery.

\section{Box 3. Concepts in the field: Local knowledge for climate change}

A 2011 project on local knowledge for climate change adaptation in Indonesia, the Philippines and Timor-Leste has worked to document local knowledge and practices to help communities predict, mitigate and adapt to hazards. They have also produced tools to integrate local knowledge within the response. This also resulted in a series of recommendations aimed at policymakers.

Community networks and relationships, or the connectedness of a community, is core to its resilience. This is defined by links within and between communities, based on social or kin relationships. ${ }^{2}$ Other aspects of a community network are social capital and social cohesion, which define the level of connectedness and the strength or weaknesses of those ties. Social capital is drawn from links between social contacts, a shared sense of identity within those, and the bridges that go beyond a shared sense of identity to other network contacts. 22,23,72 The linkage between social cohesion and community resilience, ${ }^{73}$ has been recognised as important in operational work on resilience (Box 4 ). ${ }^{74}$ Social cohesion can also be understood as well-being, a sense of belonging, and social participation of community members. ${ }^{75}$

\section{Box 4. Concepts in the field: Community solidarity following a disaster}

The Inter-American Foundation presented lessons from the 2017 Mexican earthquake to inform the COVID-19 response. They highlighted the importance of prioritising the building of community solidarity. To quickly respond to the disaster, local community organisations drew on their networks and connections to distribute emergency supplies. A sense of ownership over this process helped to increase local acceptability as locally-sourced supplies were redistributed. 
Effective communication requires the recognition and establishment of appropriate and trusted communication channels to be used before, during, and after a crisis., 2 Preliminary communication work should include the 'creation of common meanings and understandings' and established ways for community members to raise concerns and articulate attitudes ${ }^{6}$ so that these can be used when engaging with communities. For example, the IRC worked with communities to create Early Warning Systems as a part of disaster risk reduction programming. ${ }^{76}$ Strong communication channels are critical to communicate threats, ways to address them, and coordinate responses. ${ }^{77-79}$ The IFRC and

Red Cross Red Crescent National Societies have implemented community-based surveillance for human and zoonotic diseases (Box 5). ${ }^{80}$

Box 5. Concepts in the field: Community-based surveillance (see Byrne \& Nichol, 2020) IFRC's community-based surveillance programme focuses on supporting a community's role in identifying outbreak risks, recognising and notifying community members of epidemic alerts, and taking early action to control disease spread. The community-based surveillance model has yielded earlier detection and action to slow or stop outbreaks in an earlier phase of disease spread. Community engagement, capacity building, monitoring and response actions, and collaborative relationships with stakeholders are key pillars of this program that envisions communities as key actors in global health security.

\section{Governance and leadership shape how communities handle crises (Box 6). ${ }^{81}$} Communities need to be able to trust that their local leaders have their best interests at heart and are transparent in their actions. ${ }^{82,83}$ In Liberia, communities with strong and trusted local leadership, who provided accurate information about Ebola through trusted communication channels, were more likely to adapt their behaviours than communities with weak or untrusted leadership. ${ }^{21}$ Humanitarian organisations and others engaged in resilience programming could work with existing community leaders and organisations, to improve relevance and uptake of activities.

\section{Box 6. Concepts in the field: Inclusive governance for community resilience}

CARE International's work on community resilience includes a component on inclusive governance, the absence of which drives vulnerability. Their Adaptation Learning Program (ALP) works with households to promote community-based adaptation (CBA) approaches, such as Community Adaptation Action Plans (CAAPs) designed by community members to promote specific priorities. One CAAP process in Northern Ghana resulted in better linkages between government officials and community members.

Resources. Communities are more resilient when they have adequate basic resources to respond and cope with crisis (Box 7)." These may include food stocks, clean water, medical supplies, access to health facilities and veterinary staff, shelter, and so on. ${ }^{2}$ Community health and animal health workers can play a key role in detecting outbreaks early and sharing key messages as trusted sources of information in their communities. This 
category might also include livelihood resources, like space, materials and supplies, and markets." It is crucial that external support is rapidly mobilised during shocks, particularly for the most vulnerable communities who have few material resources and poor access to services. The COVID-19 pandemic has also demonstrated the need for government social protection programmes that are robust, and inclusive of vulnerable groups like refugees or migrant workers. ${ }^{51}$

\section{Box 7. Concepts in the field: Resources for resilience}

Mercy Corps' work to strengthen and support positive coping and adaptation was examined in their Rapid Strategic Resilience Assessment (STRESS) report on the Rohingya Crisis in Cox's Bazar, Bangladesh. One dimension of this was to assess Rohingya refugees' livelihood strategies in a context of economic security. Mercy Corps found that a lack of access to markets and income generation has limited people's ability to enact positive coping strategies. Many refugees had limited opportunities for paid employment, making them vulnerable to trafficking and/or exploitation. While many reported having livelihood skills, they lacked livelihood resources to put these skills to use.

\section{CONCLUSION}

While much has been learned from research and practice on community resilience, there is a need to further adapt it in ways that respond to local context and inequalities. A community resilience approach that is oriented to social-justice or is transformative, will be critical in future resilience programs, including those that address epidemic shocks. A systems approach would integrate resilience across multiple scales and sectors. These are tenets of a more localised, adaptable, and contextually-informed epidemic response. Epidemic response actors are already bridging the health/resilience gap through the engagement and support of communities, specifically by training volunteers or conducting community-based surveillance. Epidemic preparedness and response could further integrate a community resilience approach, to explicitly 1) address the social context driving the impact and spread of an epidemic and mitigate local vulnerabilities,

2) leverage existing community capacities and local knowledge, and 3) help a community to cope with the complexity of future epidemic shocks. However, additional research and practice is needed to further develop this.

\section{OTHER RESOURCES}

- Care International. (2020). Understanding Resilience: Perspectives from Syrians. https://www.care-international.org/

- International Federation of Red Cross and Red Crescent Societies (IFRC). (2014). IFRC Framework for Community Resilience. 
- International Rescue Committee (IRC). (2018). From Response to Resilience: Working with Cities and City Plans to Address Urban Displacement. https://www.rescue.org/

- Mercy Corps. Strategic Resilience Assessment (STRESS):

https://www.mercycorps.org/

- Oxfam. (2015). A Companion Guide to Resilience: https://www-con.oxfam.org/s3fspublic/file_attachments/ml-companion-guide-resilience-040216-en_o.pdf

\section{ACKNOWLEDGMENTS}

We would like to thank Kelsey Weber (International Rescue Committee), Julianne Birungi (UNICEF), Caroline Austin (IFRC), Maya Schaerer (IFRC), Gwendolen Eamer (IFRC), Danielle Jolicoeur (Mercy Corps), Annie Wilkinson (Institute of Development Studies), and Olivia Tulloch (Anthrologica) who provided scientific review of the brief and Karla Peña (Mercy Corps) for input.

\section{CONTACT}

If you have a direct request concerning the response to COVID-19, regarding a brief, tools, additional technical expertise or remote analysis, or should you like to be considered for the network of advisers, please contact the Social Science in Humanitarian Action Platform by emailing Annie Lowden (a.lowden@ids.ac.uk) or (oliviatulloch@anthrologica.com). Key Platform liaison points include: UNICEF (nnaqvi@unicef.org); IFRC (ombretta.baggio@ifrc.org); and GOARN Research Social Science Group (nina.gobat@phc.ox.ac.uk).
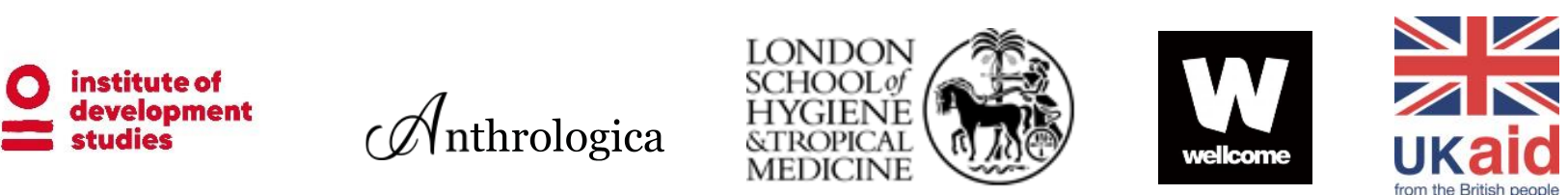

The Social Science in Humanitarian Action is a partnership between the Institute of Development Studies, Anthrologica and the London School of Hygiene and Tropical Medicine. Funding to support the Platform's response to COVID-19 has been provided by the Wellcome Trust and FCDO. The opinions expressed are those of the authors and do not necessarily reflect the views or policies of IDS, Anthrologica, LSHTM, Wellcome Trust or the UK government. 


\title{
Suggested citation: Schmidt-Sane, M., Hrynick, T., Niederberger, E., 'Community Resilience: Key Concepts and their Applications to Epidemic Shocks,' Brighton: Social Science in Humanitarian Action (SSHAP) DOI: 10.19088/SSHAP.2021.003
}

\author{
Published January 2021
}

(c) Institute of Development Studies 2021

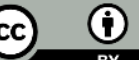

This is an Open Access paper distributed under the terms of the Creative Commons Attribution 4.0 International licence (CC BY), which permits unrestricted use, distribution, and reproduction in any medium, provided the original authors and source are credited and any modifications or adaptations are indicated.

http://creativecommons.org/licenses/by/4.0/legalcode

\section{REFERENCES}

1. Shadmi, E., Chen, Y., Dourado, I., Faran-Perach, I., Furler, J., Hangoma, P., Hanvoravongchai, P., Obando, C., Petrosyan, V., Rao, K. D., Ruano, A. L., Shi, L., de Souza, L. E., Spitzer-Shohat, S., Sturgiss, E., Suphanchaimat, R., Uribe, M. V., \& Willems, S. (2020). Health equity and COVID-19: Global perspectives. International Journal for Equity in Health, 19(1), 104. https://doi.org/10.1186/s12939020-01218-Z

2. Patel, S. S., Rogers, M. B., Amlôt, R., \& Rubin, G. J. (2017). What Do We Mean by 'Community Resilience'? A Systematic Literature Review of How It Is Defined in the Literature. PLoS Currents, 9. https://doi.org/10.1371/currents.dis.db775aff25efc5ac4f0660ad9c9f7db2

3. Chambers, R. (1989). Editorial Introduction: Vulnerability, Coping and Policy. IDS Bulletin, 20(2), 1-7. https://doi.org/10.1111/j.17595436.1989.mp20002001.x

4. Bergstrand, K., Mayer, B., Brumback, B., \& Zhang, Y. (2015). Assessing the relationship between social vulnerability and community resilience to hazards. 122, 391-409.

5. Panter-Brick, C. (2014). Health, Risk, and Resilience: Interdisciplinary Concepts and Applications. Annual Review of Anthropology, 43(1), 431-448. https://doi.org/10.1146/annurev-anthro-102313-025944

6. Norris, F. H., Stevens, S. P., Pfefferbaum, B., Wyche, K. F., \& Pfefferbaum, R. L. (2008). Community resilience as a metaphor, theory, set of capacities, and strategy for disaster readiness. American Journal of Community Psychology, 47(1-2), 127-150. https://doi.org/10.1007/s10464-007-9156-6

7. Wilkinson, A., Parker, M., Martineau, F., \& Leach, M. (2017). Opinion piece Engaging 'communities': Anthropological insights from the West African Ebola epidemic. Royal Society, 372(1721). https://doi.org/10.1098/rstb.2016.0305

8. Gallopín, G. C. (2006). Linkages between vulnerability, resilience, and adaptive capacity. Global Environmental Change, 16(3), 293-303. https://doi.org/10.1016/j.gloenvcha.2006.02.004

9. Smit, B., \& Wandel, J. (2006). Adaptation, adaptive capacity and vulnerability. Global Environmental Change, 16(3), 282-292. https://doi.org/10.1016/j.gloenvcha.2006.03.008

10. Ganor, M., \& Ben-Lavy, Y. (2003). Community Resilience: Lessons Derived from Gilo Under Fire. Jewish Communal Service Association of North America. https://www.policyarchive.org/handle/10207/16280

11. Mercy Corps. (2018). Planting seeds of resilience in humanitarian settings: Rapid strategic resilience assessment report for the Rohingya Crisis, Cox's Bazar, Bangladesh. Mercy Corps and IOM.

12. Pfefferbaum, B., Pfefferbaum, R. L., \& Norris, F. H. (2010). Community resilience and wellness for the children exposed to Hurricane Katrina. In Helping families and communities recover from disaster: Lessons learned from hurricane Katrina and its aftermath. (pp. 265-285). American Psychological Association. https://doi.org/10.1037/12054-011

13. Rego, A., \& Mehta, S. (2005). Opportunities and challenges in risk resilient recovery. World Hospitals and Health Services: The Official Journal of the International Hospital Federation, 47(4), 33-35.

14. Kennedy, G., Richards, M., Chicarelli, M., Ernst, A., Harrell, A., \& Stites, D. (2013). Disaster mitigation: Initial response. Southern Medical Journal, 106(1), 13-16. https://doi.org/10.1097/SMJ.0b013e31827cb037

15. Moore, M., Chandra, A., \& Feeney, K. C. (2013). Building community resilience: What can the United States learn from experiences in other countries? Disaster Medicine and Public Health Preparedness, 7(3), 292-301. https://doi.org/10.1001/dmp.2012.15

16. Uscher-Pines, L., Chandra, A., \& Acosta, J. (2013). The promise and pitfalls of community resilience. In Disaster Medicine and Public Health Preparedness (Vol. 7, Issue 6, pp. 603-606). Lippincott Williams and Wilkins. https://doi.org/10.1017/dmp.2013.100

17. Nucifora, F. C., Subbarao, I., \& Hsu, E. B. (2012). Changing the paradigm: A novel framework for the study of resilience. In International Journal of Emergency Mental Health (Vol. 14, Issue 2, pp. 73-76).

18. IFRC. (2014). IFRC framework for community resilience. International Federation of the Red Cross and Red Crescent Societies (IFRC).

19. Koliou, M., van de Lindt, J. W., McAllister, T. P., Ellingwood, B. R., Dillard, M., \& Cutler, H. (2018). State of the research in community resilience: Progress and challenges. Sustainable and Resilient Infrastructure, No VOLUME. https://doi.org/10.1080/23789689.2017.1418547 
20. EU Emergency Trust Fund for Africa. (2018). Programme de développement inclusif dans les zones d'accueil (DIZA) [Text]. EU Emergency Trust Fund for Africa - European Commission. https://ec.europa.eu/trustfundforafrica/region/sahel-lakechad/tchad/programme-de-developpement-inclusif-dans-les-zones-daccueil-diza_en

21. Alonge, O., Sonkarlay, S., Gwaikolo, W., Fahim, C., Cooper, J. L., \& Peters, D. H. (2019). Understanding the role of community resilience in addressing the Ebola virus disease epidemic in Liberia: A qualitative study (community resilience in Liberia). Global Health Action, 12(1), 1662682. https://doi.org/10.1080/16549716.2019.1662682

22. Aldrich, D. P., \& Meyer, M. A. (2015). Social Capital and Community Resilience. American Behavioral Scientist, 59(2), 254-269. https://doi.org/10.1177/0002764214550299

23. Poortinga, W. (2012). Community resilience and health: The role of bonding, bridging, and linking aspects of social capital. Health and Place, 18(2), 286-295. https://doi.org/10.1016/j.healthplace.2011.09.017

24. CARE International UK. (n.d.). Understanding resilience: Perspectives from Syrians.

25. International Rescue Committee. (2018). From Response to Resilience. 48.

26. Natoli, L., Bell, V., Byrne, A., Tingberg, T., \& McClelland, A. (2020). Community Engagement to Advance the GHSA: It's About Time. Health Security, 18(4), 335-337. https://doi.org/10.1089/hs.2019.0099

27. Opinion: Putting communities at the center of disease prevention. (2017, November 13). Devex. https://www.devex.com/news/sponsored/opinion-putting-communities-at-the-center-of-disease-prevention-91507

28. Kirsch, T. D., Moseson, H., Massaquoi, M., Nyenswah, T. G., Goodermote, R., Rodriguez-Barraquer, I., Lessler, J., Cumings, D. A. T., \& Peters, D. H. (2017). Impact of interventions and the incidence of ebola virus disease in Liberia-Implications for future epidemics. Health Policy and Planning, 32(2), 205-214. https://doi.org/10.1093/heapol/czw113

29. International Rescue Committee. (2014). A different kind of army: A call to place community leadership at the center of the Ebola response.

30. Mackenzie, J. S., \& Jeggo, M. (2019). The One Health Approach-Why Is It So Important? Tropical Medicine and Infectious Disease, 4(2). https://doi.org/10.3390/tropicalmed4020088

31. Community Epidemic \& Pandemic Preparedness. (n.d.). International Federation of Red Cross and Red Crescent Societies. Retrieved 25 January 2021, from https://media.ifrc.org/ifrc/community-epidemic-pandemic-preparedness/

32. Mihunov, V. V., Lam, N. S. N., Rohli, R. V., \& Zou, L. (2019). Emerging disparities in community resilience to drought hazard in southcentral United States. International Journal of Disaster Risk Reduction, 41, 101302. https://doi.org/10.1016/j.ijdrr.2019.101302

33. Santana Rangel, J. A., Arenas Monreal, L., \& Ramsey, J. M. (2016). Community resilience and Chagas disease in a rural region of Mexico. Revista De Saude Publica, 50, 46. https://doi.org/10.1590/S1518-8787.2016050005911

34. Huber, A., Gorostiza, S., Kotsila, P., Beltrán, M. J., \& Armiero, M. (2017). Beyond "Socially Constructed" Disasters: Re-politicizing the Debate on Large Dams through a Political Ecology of Risk. Capitalism Nature Socialism, 28(3), 48-68. https://doi.org/10.1080/10455752.2016.1225222

35. Vickery, J. (2019). Chapter 6 - Homelessness and inequality in the U.S.: Challenges for community disaster resilience. In F. I. Rivera (Ed.), Emerging Voices in Natural Hazards Research (pp. 145-177). Butterworth-Heinemann. https://doi.org/10.1016/B978-0-12-815821$0.00013-8$

36. Doorn, N., Gardoni, P., \& Murphy, C. (2019). A multidisciplinary definition and evaluation of resilience: The role of social justice in defining resilience. Sustainable and Resilient Infrastructure, 4(3), 112-123. https://doi.org/10.1080/23789689.2018.1428162

37. Ramcilovic-Suominen, S., \& Kotilainen, J. (2020). Power relations in community resilience and politics of shifting cultivation in Laos. Forest Policy and Economics, 175, 102159. https://doi.org/10.1016/j.forpol.2020.102159

38. Ebola, tsunamis and droughts-How gender inequality undermines community resilience / PCI (Project Concern International). (n.d.). Retrieved 28 August 2020, from https:/www.pciglobal.org/ebola-tsunamis-and-droughts-how-gender-inequalityundermines-community-resilience/

39. CARE Australia. (2016). Enhancing resilience through gender equality.

40. Rippon, S., Bagnall, A.-M., Gamsu, M., South, J., Trigwell, J., Southby, K., Warwick-Booth, L., Coan, S., \& Woodward, J. (2020). Towards transformative resilience: Community, neighbourhood and system responses during the COVID-19 pandemic. Cities \& Health O(0), 1-4. https://doi.org/10.1080/23748834.2020.1788321

41. Why building 'resilience' matters, and needs to confront injustice and inequality. (2013, May 21). From Poverty to Power. https://oxfamblogs.org/fp2p/why-building-resilience-matters-and-needs-to-confront-injustice-and-inequality/

42. Jurjonas, M., \& Seekamp, E. (2018). Rural coastal community resilience: Assessing a framework in eastern North Carolina. Ocean \& Coastal Management, 162, 137-150. https://doi.org/10.1016/j.ocecoaman.2017.10.010

43. Cutter, S. L. (2016). Resilience to What? Resilience for Whom? The Geographical Journal, 182(2), 110-113. https://doi.org/10.1111/geoj.12174

44. Doorn, N. (2017). Resilience indicators: Opportunities for including distributive justice concerns in disaster management. Journal of Risk Research, 20(6), 711-731. https://doi.org/10.1080/13669877.2015.1100662

45. Doorn, N. (2019). How can resilient infrastructures contribute to social justice? Preface to the special issue of sustainable and resilient infrastructure on resilience infrastructures and social justice. Sustainable and Resilient Infrastructure, 4(3), 99-102. https://doi.org/10.1080/23789689.2019.1574515

46. McEvoy, D., Fünfgeld, H., \& Bosomworth, K. (2013). Resilience and Climate Change Adaptation: The Importance of Framing. Planning Practice \& Research, 28(3), 280-293. https://doi.org/10.1080/02697459.2013.787710

47. Atallah, D. G., Bacigalupe, G., \& Repetto, P. (2019). Centering at the Margins: Critical Community Resilience Praxis. Journal of Humanistic Psychology, 0022167818825305. https://doi.org/10.1177/0022167818825305

48. Allmark, P., Bhanbhro, S., \& Chrisp, T. (2014). An argument against the focus on Community Resilience in Public Health. BMC Public Health, 14, 62. https://doi.org/10.1186/1471-2458-14-62

49. Pasteur, K., \& McQuistan, C. (2016). From Risk to Resilience: A systems approach to building long-term, adaptive wellbeing for the most vulnerable. https://doi.org/10.3362/9781780447070

50. Harrison, C. G., \& Williams, P. R. (2016). A systems approach to natural disaster resilience. Simulation Modelling Practice and Theory, 65, 11-31. https://doi.org/10.1016/j.simpat.2016.02.008

51. Schmidt-Sane, M., Wilkinson, A., \& Ripoll, S. (2020). COVID-19 Management in Marginalised Populations in Southeast Asia. Social Science in Humanitarian Action (SSHAP). http://ssia.local/resources/key-considerations-covid-19-management-marginalisedpopulations-southeast-asia-transnational-migrants-informal-workers-people-living-informal-settlements/

52. South, J., Stansfield, J., Amlôt, R., \& Weston, D. (2020). Sustaining and strengthening community resilience throughout the COVID-19 pandemic and beyond: Perspectives in Public Health. https://doi.org/10.1177/1757913920949582 
53. Barker, K. M., Ling, E. J., Fallah, M., VanDeBogert, B., Kodl, Y., Macauley, R. J., Viswanath, K., \& Kruk, M. E. (2020). Community engagement for health system resilience: Evidence from Liberia's Ebola epidemic. Health Policy and Planning, 35(4), 416-423. https://doi.org/10.1093/heapol/czz174

54. Kieny, M.-P., Evans, D. B., Schmets, G., \& Kadandale, S. (2014). Health-system resilience: Reflections on the Ebola crisis in western Africa. Bulletin of the World Health Organization, 92(12), 850. https://doi.org/10.2471/BLT.14.149278

55. Kruk, M. E., Myers, M., Varpilah, S. T., \& Dahn, B. T. (2015). What is a resilient health system? Lessons from Ebola. The Lancet, 385(9980), 1910-1912. https://doi.org/10.1016/S0140-6736(15)60755-3

56. Siekmans, K., Sohani, S., Boima, T., Koffa, F., Basil, L., \& Laaziz, S. (2017). Community-based health care is an essential component of a resilient health system: Evidence from Ebola outbreak in Liberia. BMC Public Health, 17(1), 84. https://doi.org/10.1186/s12889-0164012-y

57. Market Systems Resilience: A Framework for Measurement. (2019, October 4). https://www.usaid.gov/documents/1866/marketsystems-resilience-framework-measurement

58. Downing, J., Field, M., Ripley, M., \& Sebstad, J. (2018). Market systems resilience: A framework for measurement. USAID.

59. Food System Resilience. (n.d.). Center for a Livable Future. Retrieved 10 December 2020, from https://clf.jhsph.edu/projects/foodsystem-resilience

60. Béné, C. (2020). Resilience of local food systems and links to food security-A review of some important concepts in the context of COVID-19 and other shocks. Food Security, 1-18.

61. Shava, S., Zazu, C., Tidball, K., \& O'Donoghue, R. (2009). Local knowledge as a source of community resilience: IKS community development and resilience. Indilinga African Journal of Indigenous Knowledge Systems, 8(2), 218-229.

62. Gaddy, H. G. (2020). Using local knowledge in emerging infectious disease research. Social Science \& Medicine, 258, 113107. https://doi.org/10.1016/j.socscimed.2020.113107

63. Abad-Franch, F., Vega, M. C., Rolón, M. S., Santos, W. S., \& Arias, A. R. de. (2011). Community Participation in Chagas Disease Vector Surveillance: Systematic Review. PLOS Neglected Tropical Diseases, 5(6), e1207. https://doi.org/10.1371/journal.pntd.0001207

64. Dickin, S. K., Schuster-Wallace, C. J., \& Elliott, S. J. (2014). Mosquitoes \& vulnerable spaces: Mapping local knowledge of sites for dengue control in Seremban and Putrajaya Malaysia. Applied Geography, 46, 71-79. https://doi.org/10.1016/j.apgeog.2013.11.003

65. Tschakert, P., Ricciardi, V., Smithwick, E., Machado, M., Ferring, D., Hausermann, H., \& Bug, L. (2016). Situated knowledge of pathogenic landscapes in Ghana: Understanding the emergence of Buruli ulcer through qualitative analysis. Social Science \& Medicine, 150, 160-171. https://doi.org/10.1016/j.socscimed.2015.12.005

66. Hewlett, B. S., \& Amola, R. P. (2003). Cultural Contexts of Ebola in Northern Uganda. Emerging Infectious Diseases, 9(10), 1242-1248. https://doi.org/10.3201/eid0910.020493

67. Abramowitz, S. A., McLean, K. E., McKune, S. L., Bardosh, K. L., Fallah, M., Monger, J., Tehoungue, K., \& Omidian, P. A. (2015). CommunityCentered Responses to Ebola in Urban Liberia: The View from Below. PLOS Neglected Tropical Diseases, 9(4), e0003706. https://doi.org/10.1371/journal.pntd.0003706

68. Richards, P., Honwana, A., Waal, A. de, Dowden, R., \& Kitchen, S. (2016). Ebola: How a People's Science Helped End an Epidemic (Illustrated edition). Zed Books.

69. Hiwasaki, L., Luna, E., Syamsidik, \& Shaw, R. (2014). Local and indigenous knowledge for community resilience: Hydro-meteorological disaster risk reduction and climate change adaptation in coastal and small island communities. UNESCO. https://unesdoc.unesco.org/ark:/48223/pfo000228711

70. ECBHFA / Community based health and first aid. (n.d.). Retrieved 25 January 2021, from https://ifrc-eclohfa.org/

71. Epidemic Control for Volunteers. (n.d.). Retrieved 25 January 2021, from https://ifrcgo.org/ecv-toolkit/

72. Bourdieu, P. (1986). The forms of capital. In J. Richardson (Ed.), Handbook of Theory and Research for the Sociology of Educaiton. Greenwood.

73. Patel, R. B., \& Gleason, K. M. (2018). The association between social cohesion and community resilience in two urban slums of Port au Prince, Haiti. International Journal of Disaster Risk Reduction, 27, 161-167. https://doi.org/10.1016/j.ijdrr.2017.10.003

74. Community Resilience in the Time of COVID-19: Lessons from the 2017 Mexican Earthquakes · Inter-American Foundation. (n.d.). Inter-American Foundation. Retrieved 7 October 2020, from https://www.iaf.gov/content/story/community-resilience-in-thetime-of-covid-19/

75. Townshend, I., Awosoga, O., Kulig, J., \& Fan, H. (2015). Social cohesion and resilience across communities that have experienced a disaster. Natural Hazards, 76(2), 913-938. https://doi.org/10.1007/s11069-014-1526-4

76. Early detection, early action: Preventing DRC's Ebola outbreak from spreading into nearby Uganda. (n.d.). International Federation of Red Cross and Red Crescent Societies. Retrieved 25 January 2021, from https://media.ifrc.org/ifrc/2019/01/26/early-detectionearly-action-preventing-drcs-ebola-outbreak-spreading-nearby-uganda-2/

77. Chandra, A., Acosta, J., Howard, S., Uscher-Pines, L., Williams, M., Yeung, D., Garnett, J., \& Meredith, L. S. (2011). Building Community Resilience to Disasters. Rand Health Quarterly, 7(1). https://www.ncbi.nlm.nih.gov/pmc/articles/PMC4945213/

78. Liu, B. F., Fowler, B. M., Roberts, H. A., Sayers, E. L. P., \& Egnoto, M. J. (2017). The role of communication in healthcare systems and community resilience. International Journal of Emergency Management, 73(4), 305-327.

79. IFRC. (2016). The IFRC and community resilience: Communication guidance for National Societies. International Federation of the Red Cross and Red Crescent Societies.

80. Byrne, A., \& Nichol, B. (2020). A community-centred approach to global health security: Implementation experience of communitybased surveillance (CBS) for epidemic preparedness. Global Security: Health, Science and Policy, 5(1), 71-84. https://doi.org/10.1080/23779497.2020.1819854

81. Kapucu, N., \& Sadiq, A.-A. (2016). Disaster Policies and Governance: Promoting Community Resilience. Publisher. https://scholarworks.iupui.edu/handle/1805/12003

82. Sobeck, J., Smith-Darden, J., Hicks, M., Kernsmith, P., Kilgore, P. E., Treemore-Spears, L., \& McElmurry, S. (2020). Stress, Coping, Resilience and Trust during the Flint Water Crisis. Behavioral Medicine, 46(3-4), 202-216. https://doi.org/10.1080/08964289.2020.1729085

83. CARE International. (2016). Increasing resilience: Theoretical guidance document for CARE International 